Research Article

\title{
Spectral Variation and Corresponding Changing Mechanism of Suspended Particulate Material Absorption in Poyang Lake during Flood Periods
}

\author{
Yuandong Wang $\mathbb{D}^{1},{ }^{1,2}$ Xibin You, ${ }^{1}$ Lianfang Yu, ${ }^{1}$ Lihong Meng, ${ }^{1}$ Xiangming Xu, ${ }^{1}$ \\ and Guangxu Liu ${ }^{1}$ \\ ${ }^{1}$ College of Geography and Planning, Gannan Normal University, Ganzhou 341000, China \\ ${ }^{2}$ Key Laboratory of Digital Earth Science, Institute of Remote Sensing and Digital Earth, Chinese Academy of Sciences, \\ Beijing 100094, China
}

Correspondence should be addressed to Yuandong Wang; ydwang@yic.ac.cn

Received 9 June 2018; Accepted 30 July 2018; Published 25 September 2018

Academic Editor: Jose R. B. Cantalice

Copyright (c) 2018 Yuandong Wang et al. This is an open access article distributed under the Creative Commons Attribution License, which permits unrestricted use, distribution, and reproduction in any medium, provided the original work is properly cited.

\begin{abstract}
Remote sensing accuracy of the dynamic water environment under a changing environment due to climate and anthropogenic impacts should be improved by a deep understanding of the absorption properties pertinent to the water body. Spectral variation of suspended particulate material (SPM) absorption and its changing mechanism during flood periods of Poyang Lake were analyzed in this study. Absorption coefficients were measured and determined by spectrophotometry using the quantitative filter techniques (QFTs) based on field samples from July 12 to September 06, 2017. Two main optical active constituents (OACs) of SPM including nonalgal and phytoplankton algal particulates were quantified and analyzed in detail. The results suggested that, during study periods, Poyang Lake exhibits an overall high level of suspended nonalgal detritus and algal concentration and lower water clarity, showing a strong absorption by total suspended sediments that are closely related with the land-derived nonalgal detritus material which varied significantly with diverse proportions of minerals and organic materials from multiple sources. Due to variations in phytoplankton community pigment composition, concentration, and package effect, there exists a difference between optical absorption capacity on blue (440) and red (675) portions of bands, the former of which had an obvious enhancement due to the increased effect of accessory pigments in suspended phytoplankton particles from July to September. Evidence also presented that the nonlinear dependency of specific phytoplankton particulate absorption on pigment concentration for various trophic statuses in different periods could be unstable due to relative contributions of the package effect and accessory pigments; this could bring uncertainties to the parameterization of optical models and remote sensing algorithms proposed for accurate applications in lake water environment monitoring.
\end{abstract}

\section{Introduction}

Absorption coefficients of optical active constituents (OACs, i.e., particulate and dissolved materials) play an important role in the inherent optical properties (IOPs, i.e., absorption and specific coefficients), largely determining the apparent optical properties (AOPs, i.e., water leaving radiance and remote sensing reflectance) in natural waters $[1,2]$. Therefore, remote sensing inversion accuracy of the dynamic water environment under a changing environment due to climate and anthropogenic disturbances should be improved by a deep understanding of the absorption properties pertinent to the water body under consideration [3-5].

Over past decades, variability in absorption coefficients has been thoroughly documented in oceanic waters (the socalled "Case 1"), where phytoplankton and their derivative products (organic detritus and dissolved yellow substance, arising by zooplankton grazing, or natural decay of the algal cells) are optically dominant, and other components are often assumed to covary with phytoplankton pigments [6-10]. Due to the simple configuration of Case 1 waters, single OAC models and algorithms based solely upon 
phytoplankton have performed satisfactorily in oceanic waters [9, 11-13].

However, absorption coefficients can show significant variability in space and time in inland waters, where nonalgal particles consist of minerals and nonliving organics detritus such as feccal material or degrading phytoplankton cells are not proportional to phytoplankton. Therefore, models and algorithms based solely upon chlorophyllbearing biota are often invalid when applied to inland waters that spread across different geographic regions [14-16].

In recent years, there has been an increasing focus on the environment responses of inland waters due to climate and anthropogenic impacts, wherein spectral properties are very often dominated by land-derived inorganic or organic suspended particulate materials (SPMs) [17-22]. As the largest fresh water lake in China, Poyang Lake is in a very dynamic hydrological environment with the complex benthic topography, and its water level is further fluctuated due to frequent occurrence of extreme climate events such as heavy precipitation and storms during flood periods [25]; besides, anthropogenic activities also impact the lake environment [17]. According to previous research, water clarity of most of the lake region is between 0 and $2 \mathrm{~m}$ and sediment material concentration could vary between 2.6 and $220.19 \mathrm{mg} / \mathrm{L}$ throughout the year [18]. The water quality, quantity, and aquatic conditions of Poyang Lake have great impact on downstream, middle, and lower Yangtze River and the East China seashore [17].

Many researchers have performed studies in this region, and they provided valuable evidence of the optical properties of suspended substances [23-25]. Chen et al. revealed that the partition of organic and inorganic materials is helpful to accurately determine the optical property of SPM [22]. $\mathrm{Wu}$ et al. confirmed the temporal and regional variability of specific inherent optical properties due to different water constituents [24], and the development of the regional SPM model is fundamental for managing and protecting aquatic ecosystems [25].

Therefore, the complex spectral behavior of suspended sediments due to various OAC composition dynamics under evolving hydrological conditions in a changing climate still needs further investigation. Understanding more of variability in IOPs and the processes acting to change the optical behavior of suspended materials can be helpful to improve the accuracy of water quality parameters retrieval using remote sensing techniques for this complex water environment. To establish regional satellite algorithms aimed at evaluation of the content of suspended materials across different time spans for this dynamic lake, it is necessary to quantify the dependence of absorption coefficients on their OAC concentration at feature wavelengths, exploring corresponding contribution effects on the spectral change.

The main objectives of this study are (1) to separate absorption coefficients of suspended particulate materials in Poyang Lake through controlled laboratory experiments during the flood period, which may have its own characteristics at this time, contributing to a better understanding of the optical behavior of SPM absorption, and (2) to clarify the changing mechanism for corresponding components of absorption, which may facilitate improvements in the parameterization of remote sensing algorithms for the interpretation of remote sensing information.

\section{Materials and Methods}

2.1. Study Area. Poyang Lake $\left(115^{\circ} 47^{\prime}-116^{\circ} 45^{\prime} \mathrm{E}\right.$, $\left.28^{\circ} 22^{\prime}-29^{\circ} 45^{\prime} \mathrm{N}\right)$ is situated at the lower Yangtze River basin (Figure 1), with a subtropical monsoon climate and a mean annual precipitation of $1680 \mathrm{~mm}$ [26]. It is fed by tributaries of five rivers of Ganjiang, Fuhe, Xinjiang, Raohe, and Xiushui, connecting to and exchanging water with Yangtze River through the lake mouth in the north. The water level is highly dynamic with significant fluctuations throughout the year, with an extending water surface area (maximum to $4000 \mathrm{~km}^{2}$ ) during the flood period between April and September and then shrinking during the dry period between October and March [27]. Meanwhile, the impact of anthropogenic activities on the lake water environment such as major hydrologic engineering and sand mining have caught attentions and been reported $[28,29]$. Therefore, the lake water environment is under both natural and anthropogenic influences, providing a wide range of IOPs and OACs.

2.2. Sampling Details. The present work was carried out on boats, and a total of 55 water samples were collected in Lake Poyang from July 12 to 19 and September 01 to 06 in 2017, which is the representative time of flood periods when water level is at a status of increasingly high. Considering the lake geometry shape and hydrological flow directions, sample points were at about $5 \mathrm{~km}$ intervals and sampling locations were kept as same as possible between two survey periods; 15 samples were excluded in statistical analysis due to large distance discrepancies and outliers beyond 2 standard deviations of the mean. At each location, water samples prepared for the particulate absorption measurement were collected from the surface to about $20 \mathrm{~cm}$ below in the vertical direction, which were then stored in ice bags and transported to the laboratory for determinations in time. Water transparency was also recorded with the Secchi disk (SD), and geographical locations of sample sites were positioned and navigated using handheld GPS (Figure 1).

2.3. Laboratory Measurements. In the laboratory, the extraction and measurement of the chlorophyll a concentration (referred to as Chl.a) were made with acetone following the SM $10200 \mathrm{H}$ spectrophotometric method [15]. Total suspended particulate material (SPM) concentrations were measured gravimetrically on preweighed Whatman GF/F filters after rinsing with distilled water.

Light absorption measurements were performed using the standard procedure of the quantitative filter technique (QFT) after the suspended particles concentrated onto Whatman GF/F filters [7]. Optical density of particulate matter was measured between 350 and $800 \mathrm{~nm}$ at $1 \mathrm{~nm}$ 


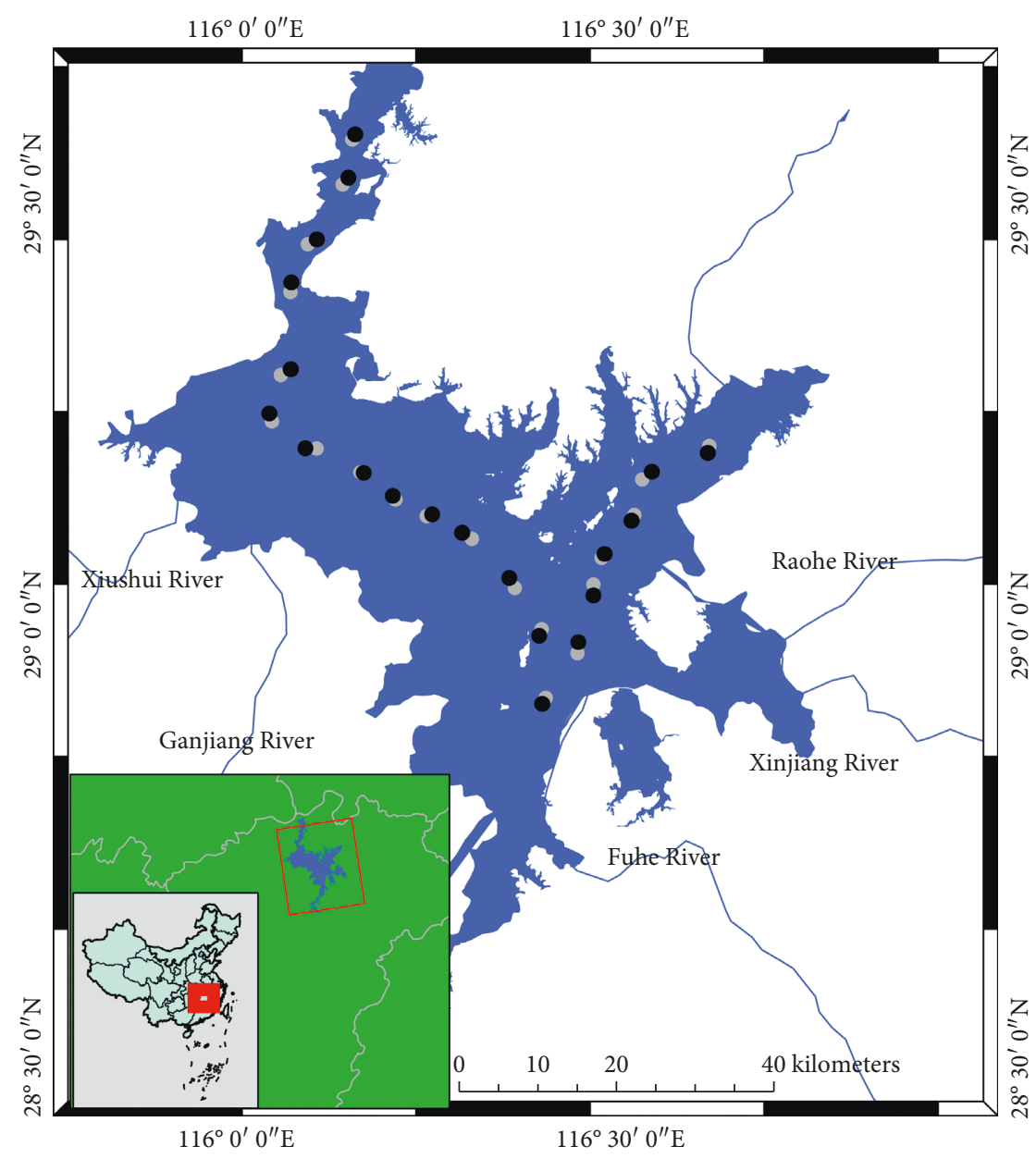

Sample points

- $07 / 12-07 / 19$

- 09/01-09/06

Figure 1: Location of Poyang Lake in China and sample sites over the lake during study periods.

intervals with a dual-beam scanning spectrophotometer with a blank filter saturated with distilled water as a reference. Nonalgal particle values were then determined after pigment extraction with pure methanol [7]. Statistical analysis was performed after measurements, descriptive statistics, one-way ANOVA, and correlation analysis were performed for Chl.a, SPM, and SD (Section 3), with null hypothesis stating the means of all levels are equal and alternative hypothesis stating the means of one or more levels are different at two periods. The correlation coefficient $\left(R^{2}\right)$ is used to describe the strength of correlation using the guide that Evans (1996) suggested: 0.00-0.19 (very weak), 0.200.39 (weak), $0.40-0.59$ (moderate), $0.60-0.79$ (strong), and $0.80-1.0$ (very strong) [30].

2.4. Analysis Methods. The absorption spectra of $\operatorname{SPM}\left(a_{\mathrm{p}}\right)$ are decomposed into nonalgal $\left(a_{\mathrm{NAP}}\right)$ and phytoplankton $\left(a_{\mathrm{ph}}\right)$ algal components. $a_{\mathrm{p}}$ and $a_{\mathrm{NAP}}$ were calculated by converting total and extracted optical densities, respectively (Equation (1)). The absorption spectra for phytoplankton $\left(a_{\mathrm{ph}}\right)$ were computed as the difference between $a_{\mathrm{p}}$ and $a_{\mathrm{NAP}}$ (Equation (2)):

$$
\begin{aligned}
a_{\mathrm{p}}(\lambda) & =\frac{2.303\left[\mathrm{OD}_{\mathrm{s}}(\lambda)-\mathrm{OD}_{(\text {null })}\right]}{\beta\left(V_{\mathrm{f}}\right) / A_{\mathrm{f}}}, \\
a_{\mathrm{ph}}(\lambda) & =a_{\mathrm{p}}(\lambda)-a_{\mathrm{NAP}}(\lambda),
\end{aligned}
$$

where $\mathrm{OD}_{\mathrm{s}}(\lambda)$ is the sample absorbance, and the geometric absorption path length of the suspended material was calculated as $V_{\mathrm{f}} / A_{\mathrm{f}}$, where $V_{\mathrm{f}}$ is the volume filtered $(200 \mathrm{ml})$ and $A_{\mathrm{f}}$ is the clearance area of the filter. The path-length amplification factor beta was assumed to be a constant value of 2 after the theoretical calculations of Roesler (1998), and null point correction $\left(\mathrm{OD}_{(\mathrm{null})}\right)$ was performed by normalizing spectra to the average absorption measured between 740 and $750 \mathrm{~nm}$ assuming no wavelength dependence [31, 32].

The absorption spectrum of nonalgal particles for each sample was modeled from 380 to $600 \mathrm{~nm}$ with an exponential function using the least-squares method, and the absorption slope $(S)$ of 40 samples was derived [33, 34]: 
TABLE 1: Range of concentrations of the main OACs during two periods in 2017.

\begin{tabular}{|c|c|c|c|c|c|}
\hline Time & Points & Range & $\begin{array}{l}\mathrm{SPM} \\
(\mathrm{mg} / \mathrm{l})\end{array}$ & $\begin{array}{l}\text { Chl.a } \\
(\mu \mathrm{g} / \mathrm{l})\end{array}$ & $\mathrm{SD}(\mathrm{cm})$ \\
\hline \multirow{3}{*}{ July } & \multirow{3}{*}{20} & Mean & 45.94 & 21.48 & 26 \\
\hline & & Min & 24.48 & 9.17 & 18 \\
\hline & & Max & 56.70 & 34.77 & 32 \\
\hline \multirow{3}{*}{ September } & \multirow{3}{*}{20} & Mean & 19.67 & 13.80 & 41 \\
\hline & & Min & 7.53 & 3.73 & 32 \\
\hline & & Max & 40.3 & 21.73 & 56 \\
\hline \multirow{2}{*}{ One-way ANOVA } & \multirow{2}{*}{\multicolumn{2}{|c|}{$\begin{array}{c}F \text { value } \\
\text { Probability }>F\end{array}$}} & 89.22 & 15.48 & 78.63 \\
\hline & & & $4.93 E-10$ & $3.91 E-4$ & $3.16 E-10$ \\
\hline
\end{tabular}

Null hypothesis: the means of all levels are equal. Alternative hypothesis: the means of one or more levels are different.

$$
a_{\mathrm{NAP}}(\lambda)=a_{\mathrm{NAP}}(440) e^{(-S(\lambda-440))},
$$

where $S$ is the spectral slope, which can reveal relative proportions of minerals and organic materials for detritus in lake waters, because $S$ values generally increase when mineral content decreases [34].

The absorption capacity of the phytoplankton algal component $a_{\mathrm{ph}}(\lambda)$ per mass unit of algae can be expressed as follows $[33,34]$ :

$$
a_{\mathrm{ph}}^{*}(\lambda)=\frac{a_{\mathrm{ph}}(\lambda)}{\text { Chl.a } \cdot \mathrm{m}^{2} / \mathrm{mg}} .
$$

As $a_{\mathrm{ph}}^{*}(\lambda)$ usually changes due to package effects and pigment composition variations, the relationship between $a_{\mathrm{ph}}^{*}(\lambda)$ and Chl.a can be expressed as a power function $[33,34]$ :

$$
a_{\mathrm{ph}}^{*}(\lambda)=A(\lambda)=[\text { Chl. } \mathrm{a}]^{-B(\lambda)},
$$

where $A$ and $B$ are the wavelength-dependent, positive parameters, with the exponent $B$ representing the strength of variations of $a_{\mathrm{ph}}^{*}(\lambda)$.

\section{Results and Discussion}

The range, average level of the SPM and Chl.a, and results of one-way ANOVA are shown in Table 1. It could be seen that, at the 0.05 level, the population means of SPM and Chl. a were both significantly different between two periods.

SPM and Chl.a were higher in July than September, representing a decreasing level of suspended sediments in lake columns as water flooded during the study time. Correspondingly, lower water transparency (SD) was observed in July, indicating higher water absorption, which is in accordance with previous research [17, 23, 24].

Although the SPM is with a low composition of phytoplankton biomass (indicated by low Chl.a compared to SPM), SD exhibited some positive correlation with Chl. a $\left(R^{2}=0.56, p<0.01\right)$, compared to suspended sediments $\left(R^{2}=0.73, p<0.01\right)$ in July, suggesting that the increasing abundance of various phytoplankton species such as spirogyra, diatoms, and cyanobacteria may also be responsible for lower transparency.

Meanwhile, more evident positive correlation of SD with $\operatorname{SPM}\left(R^{2}=0.69, p<0.01\right)$ than Chl.a $\left(R^{2}=0.39, p<0.01\right)$ was also found in September, indicating that the vast shallow lake is usually dominated by suspended sediments (with a maximum value of $40.3 \mathrm{mg} / \mathrm{l}$ in this work) during this period $[17,24]$. And water clarity was still not very high (average SD of $41 \mathrm{~cm}$ ), which might be induced by resuspended sediments due to vertical convection disturbance of the water layer because of seasonal water-level fluctuations and relevant anthropogenic disturbances [17].

3.1. Variation of Total Suspended Particulate Material Absorption. Absorption spectra of SPM $\left(a_{\mathrm{p}}\right)$ of Poyang Lake can be decomposed into nonalgal $\left(a_{\mathrm{NAP}}\right)$ and phytoplankton $\left(a_{\mathrm{ph}}\right)$ algal components, which had been illustrated in previous research $[22,24]$. Spectra curves of total suspended particulate material absorption during the flood period are present in Figure 2 (solid bold line represents mean and dashed line represents standard deviation), suggesting that absorption coefficients of SPM $\left(a_{\mathrm{p}}(\lambda)\right)$ were highly variable among sample points in both July and September, due to various SPM concentrations and compositions at different sample sites.

In July, the spectral shape of SPM resembled that of nonalgal particulates, with high absorption between 400 and $450 \mathrm{~nm}$, ranging from 9.73 to $17.05 \mathrm{~m}^{-1}$ at $440 \mathrm{~nm}$, indicating strong detrital particles dominance. Apparent phytoplankton absorption peaks could only be found at $675 \mathrm{~nm}$, with much lower values between 1.93 and $5.83 \mathrm{~m}^{-1}$ and an average of $4.60 \mathrm{~m}^{-1}$ (Figure 2).

In September, magnitude of the whole spectrum (380-700 nm) decreased significantly, and the absorption feature of phytoplankton with accessory pigments appeared slightly at the short $400-450 \mathrm{~nm}$ wavelength region around $440 \mathrm{~nm}$, with values between 2.47 and $4.69 \mathrm{~m}^{-1}$. Meanwhile more evident peaks of phytoplankton absorption could be observed between 670 and $690 \mathrm{~nm}$, but still with lower values $0.66-1.64 \mathrm{~m}^{-1}$ at $675 \mathrm{~nm}$ compared to shortwave bands (Figure 2). The growing peaks of phytoplankton absorption were also identified by $\mathrm{Wu}$ (2013) from August to October in their study of 2010 and 2011 [23].

To explore possible reasons accounted for SPM absorption variation, we select $a_{\mathrm{p}}(440)$ and $a_{\mathrm{p}}(675)$ as two feature bands to represent the blue portion $(400-450 \mathrm{~nm})$ and the red portion of the visible spectrum $(670-690 \mathrm{~nm})$, respectively. Regression analysis was performed between 


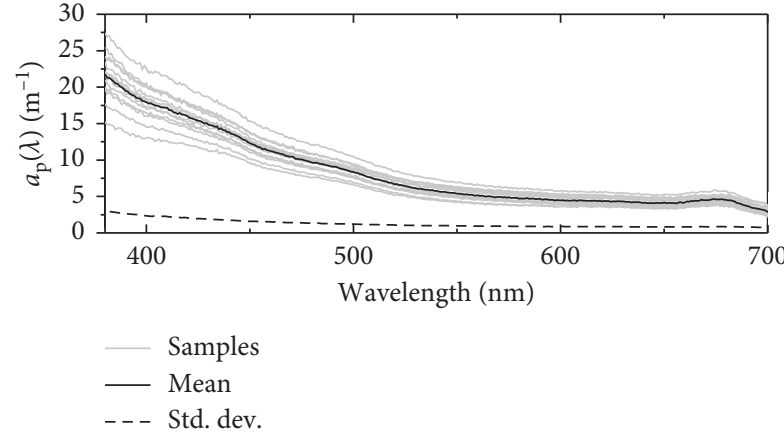

(a)

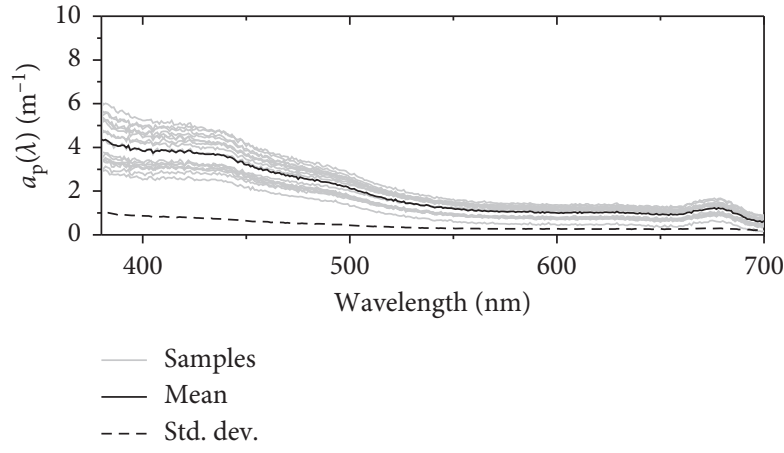

(b)

Figure 2: Total suspended particulate absorption spectra in Poyang Lake in July (a) and September (b).

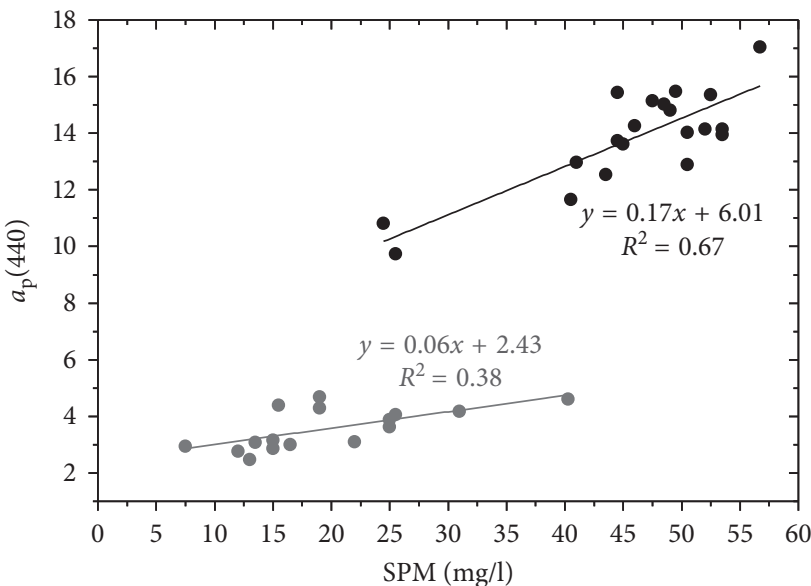

- July data

_ Linear fit in July

- September data

_ Linear fit in September

(a)

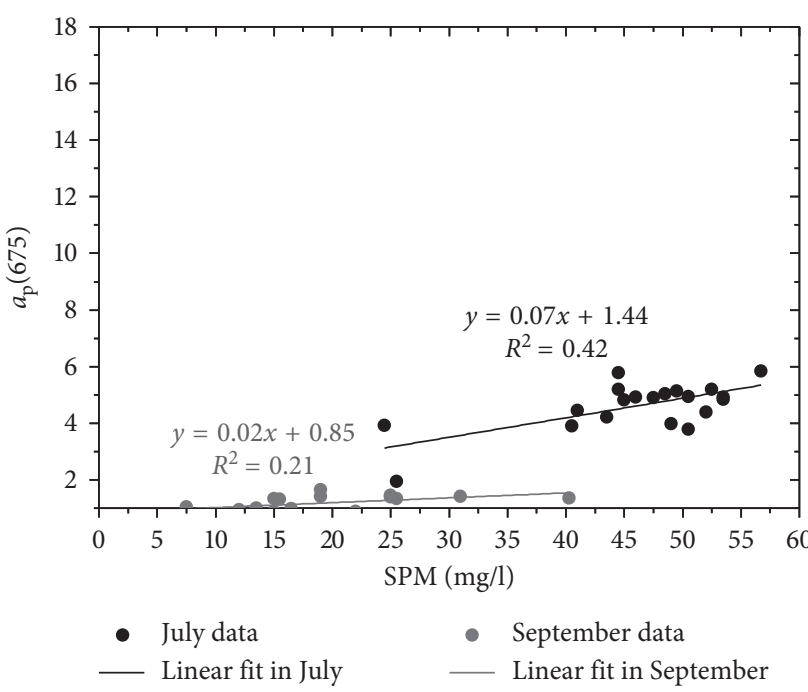

(c)

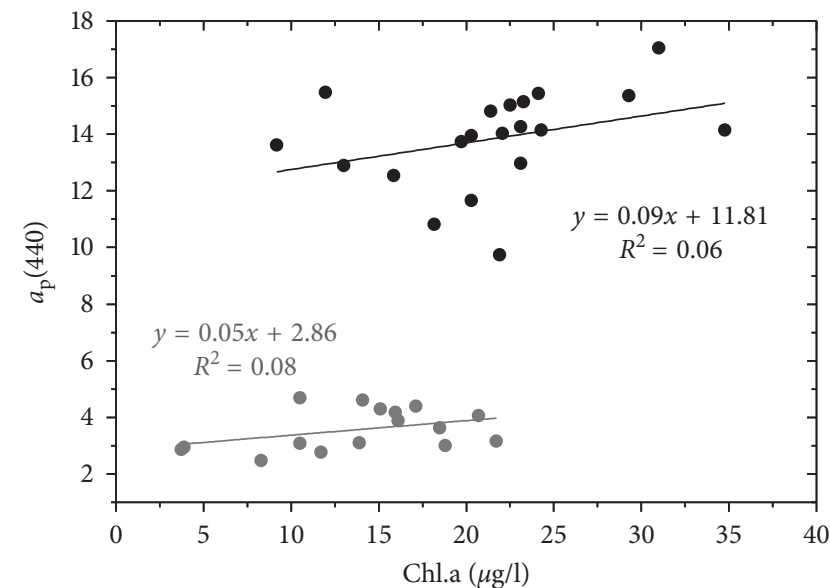

- July data

_ Linear fit in July

- September data

_ Linear fit in September

(b)

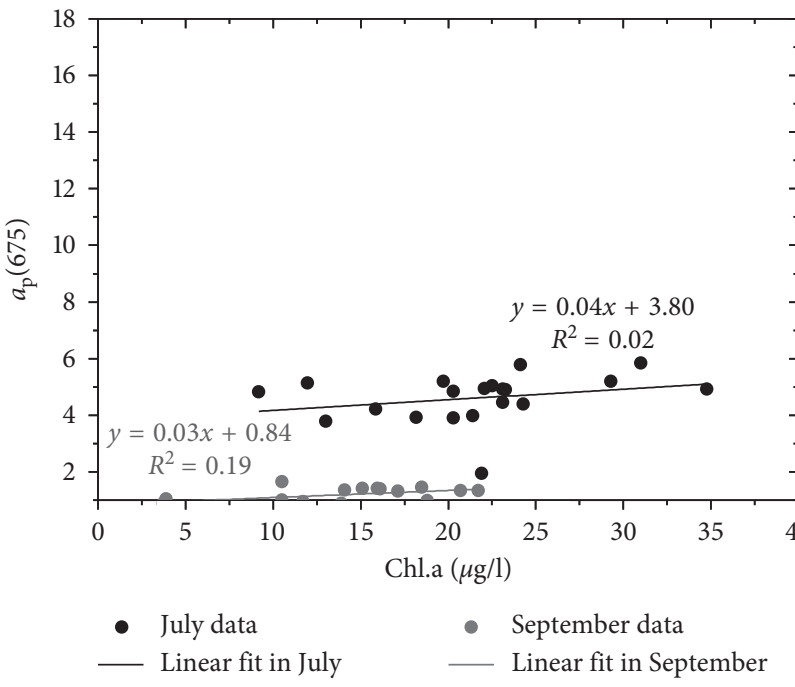

(d)

Figure 3: The linear relationships of $a_{\mathrm{p}}(440)$ and $a_{\mathrm{p}}(675)$ with SPM and Chl.a concentrations. 
$a_{\mathrm{p}}(440)$ and SPM and Chl.a, and $a_{\mathrm{p}}(675)$ and SPM and Chl. a for each period (Figure 3 ).

It could be seen that the variation of $a_{\mathrm{p}}(440)$ was more sensitive to SPM than to Chl.a for both July and September (Figures 3(a) vs 3(b)). The contribution of SPM to $a_{\mathrm{p}}(440)$ tended to decrease from July to September (Figure 3(a)) as the effect of Chl.a remained at a slightly low level (Figure 3(b)). Thus, SPM absorption in blue portion of the visible spectrum was mainly dominated by nonalgal materials in lake water columns.

And the variation of $a_{\mathrm{p}}(675)$ was also more sensitive to SPM than to Chl.a in July and September (Figures 3(c) vs 3(d)). The tendency of SPM contribution to $a_{\mathrm{p}}(675)$ also decreased from July to September (Figure 3(c)). Although there was a slight increase of Chl.a effect in September, it was still small due to the low proportion of Chl.a in SPM composition.

Although the sediments' masking effect decreased in September, nonalgal particles still dominated the absorption at wavelengths around $400-450 \mathrm{~nm}$, and contributions of phytoplankton at $600-690 \mathrm{~nm}$ were still weaker than those of nonalgal sediments. Thus, total suspended particulate material absorption during the flood period was mainly associated with detritus materials in both the blue and red spectra, which is in accordance with the results of previous research in Poyang Lake, Taihu Lake, and Chagan Lake, showing that the total SPM absorption is mainly dominated by nonalgal materials $[23,24,35,36]$.

Therefore, it is reasonable to be deduced that SPM absorption of Poyang Lake mainly has strong connection with nonalgal detritus, which will be elaborated in the next section.

3.2. Variation of Nonalgal Particulate Material Absorption. In this study, the absorption spectrum of nonalgal particles for each sample was modeled from 380 to $600 \mathrm{~nm}$ according to Equation (3) using the least-squares method, and the absorption slope $(S)$ of 40 samples was derived, from which the relative proportions of minerals and organic materials in detritus could be revealed [32].

The results showed that, in July, $S$ varied within $0.0060-0.0107 \mathrm{~nm}^{-1}$ around $0.0069 \mathrm{~nm}^{-1}$, and in September, its magnitude dropped to $0.0049-0.0102 \mathrm{~nm}^{-1}$ with an average level of $0.0067 \mathrm{~nm}^{-1}$. The variation of the detritus absorption slope could be clearly seen from absorption spectra normalized to $440 \mathrm{~nm}$ in Figure 4. It suggests that $S$ values generally decreased from July to September, indicating an elevated proportion of inorganic materials in SPM composition.

Regression analysis was also conducted between $a_{\mathrm{NAP}}(440)$ and SPM and Chl.a, and $a_{\mathrm{NAP}}(675)$ and SPM and Chl.a for each period to reveal factors responsible for variation of nonalgal material absorption in the blue region (400-450) and red region of spectra, respectively (Figure 5).

It is shown that $a_{\mathrm{NAP}}(440)$ had a much stronger relationship with SPM than with Chl.a in both July and September (Figures 5(a) vs 5(b)). From July to September, although there was slightly a decrease in SPM contribution (Figure 5(a)), the effect of Chl.a was still very low (Figure 5(b)), indicating that nonalgal sediments in the lake did not rely on phytoplankton degradation activities, which is often the case for ocean, but mainly derived from land-originated materials due to river runoff injections, such as soil surface inorganic mineral salts, reactants, nonpoint source pollutions, or decompositions of biodegradable organic compounds.

The variation of $a_{\mathrm{NAP}}(675)$ could also be attributed to SPM in two periods (Figures 5(c) vs 5(d)). The decrease of the relationship between $a_{\mathrm{NAP}}(675)$ and SPM can be observed due to the reduction of SPM concentration from July to September (Figure 5(c)). And because of the rather low proportion of phytoplankton degradation products in detritus, the significance of Chl.a effect on $a_{\mathrm{NAP}}(675)$ remained at a low level (Figure 5(d)).

It is also verified by previous research of $\mathrm{Wu}$ (2013), who showed that there were higher correlations between $a_{\mathrm{NAP}}$ and SPM in 2010 and 2011. Our results again confirm previous analysis in Section 3.1: lake SPM absorption was mainly associated with land-derived nonalgal detritus. Despite there were some decreases in September, nonalgal particles still dominated the absorption in both the blue and red spectra.

3.3. Variation of Algal Particulate Material Absorption. Specific absorption represents absorption capacity or efficiency of algal particulates in SPM. Usually, it can be used to parameterize analytical algorithms to inverse the remote sensing signal into phytoplankton pigment centration, which is closely related with the carbon fixation rate at global or regional scales $[27,33,34]$.

Spectral curves of phytoplankton particulate specific absorption derived from Equation (4) are present in Figure 6. It can be seen that $a_{\mathrm{ph}}^{*}(\lambda)$ curves in July resembled the shape pattern of absorption curves in September, and there was more evident variability at $400-500 \mathrm{~nm}$ around $440 \mathrm{~nm}$ and at $650-700 \mathrm{~nm}$ around $675 \mathrm{~nm}$.

In July, $a^{*}{ }_{\mathrm{ph}}(440)$ varied between 0.101 and $0.205 \mathrm{~m}^{2} / \mathrm{mg}$ around an average of $0.145 \mathrm{~m}^{2} / \mathrm{mg}$, and $a_{\mathrm{ph}}^{*}(675)$ was $0.056-0.111 \mathrm{~m}^{2} / \mathrm{mg}$ with a mean value of $0.084 \mathrm{~m}^{2} / \mathrm{mg}$. In September, $a_{\mathrm{ph}}^{*}(440)$ and $a_{\mathrm{ph}}^{*}(675)$ increased to $0.115-$ $0.424 \mathrm{~m}^{2} / \mathrm{mg}$ and $0.067-0.169 \mathrm{~m}^{2} / \mathrm{mg}$, with an average of $0.229 \mathrm{~m}^{2} / \mathrm{mg}$ and $0.107 \mathrm{~m}^{2} / \mathrm{mg}$, respectively.

Previous studies have demonstrated that fluctuations of $a_{\mathrm{ph}}^{*}(\lambda)$ were mainly associated with relative contributions of accessory pigments (Chl.b, Chl.c, and carotenoids) and chlorophyll present in phytoplankton cells under different light and nutrient conditions $[15,17,23,32-35]$. The increased abundance of accessory pigments tended to enhance the absorption of blue portion of the visible spectrum between 400 and $500 \mathrm{~nm}$, while Chl.a constantly leads to a contribution focusing on $650-700 \mathrm{~nm}$.

Therefore, the apparent variations of $a_{\mathrm{ph}}^{*}(\lambda)$ here suggested that there might be evident changes in phytoplankton community or pigment compositions during study periods. To validate this speculation, $a_{\mathrm{ph}}^{*}(\lambda)$ spectra were normalized to $440 \mathrm{~nm}$ in Figure 7. It could be clearly 


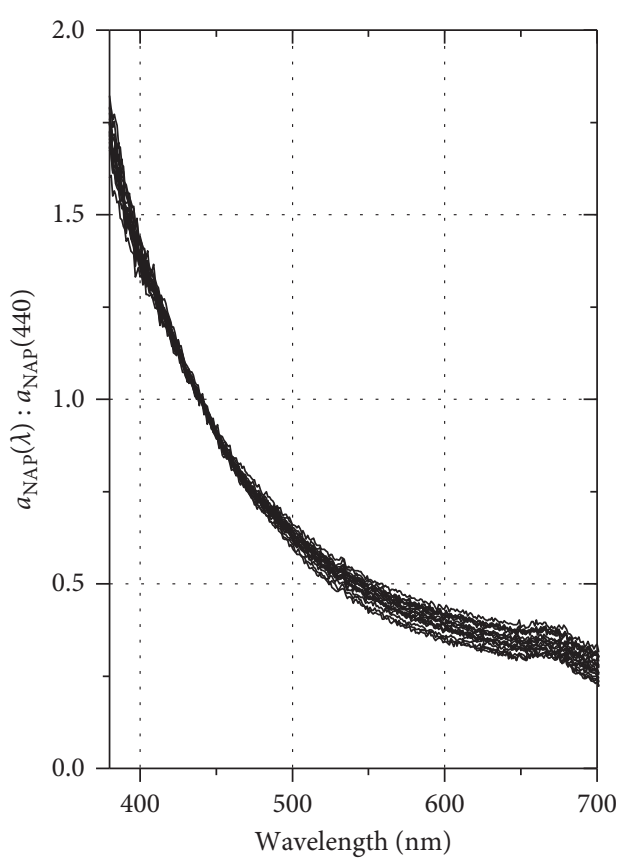

(a)

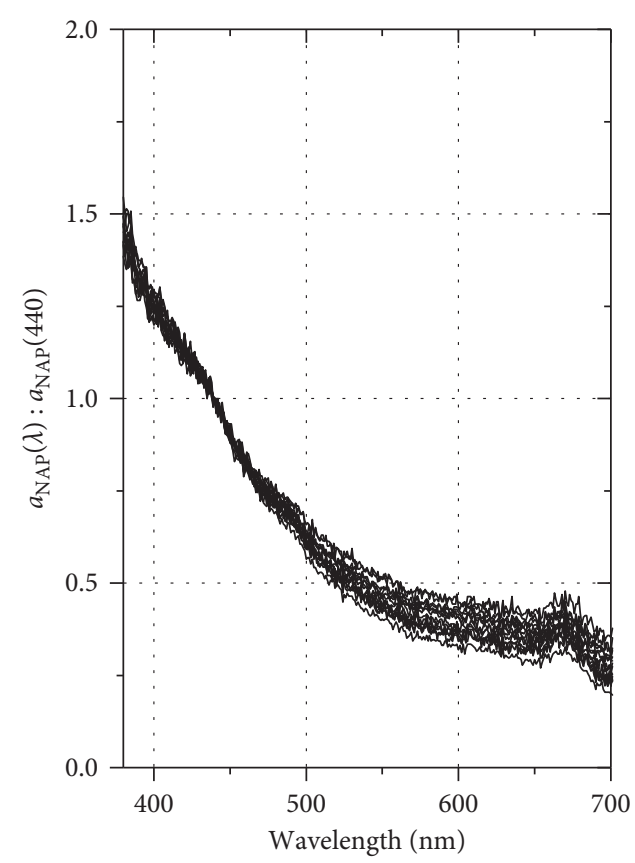

(b)

FIGURE 4: Nonalgal particulates of absorption spectra normalized to $a_{\mathrm{NAP}}(440)$ in July (a) and September (b).

seen that compared to July, the ratio values at $675 \mathrm{~nm}$ $\left(a_{\mathrm{ph}}^{*}(675): a_{\mathrm{ph}}^{*}(440)\right)$ in September had decreased, exhibiting an increased effect of accessory pigments (Chl. b, Chl.c, and carotenoids).

While changes in optical absorption capacity in blue (at $440 \mathrm{~nm}$ ) and red (at $675 \mathrm{~nm}$ ) portions could be the consequence of pigment composition changes, the possible differences in the pigment concentration level and package effect in the specific trophic status during study periods may also be responsible for that.

Therefore, the variation of $a_{\mathrm{ph}}^{*}(\lambda)$ due to pigment concentration (indicated by Chl.a) change was further analyzed using Equation (5), from which the strength of variations in $a_{\mathrm{ph}}^{*}(\lambda)$ could be inferred by the exponent $B$ (Figure 8).

Despite the fact that there was some dispersion, $a_{\mathrm{ph}}^{*}(\lambda)$ exhibited a decreasing trend with increasing pigment concentration at $440 \mathrm{~nm}$ and $675 \mathrm{~nm}$ (Figure 8). To some extent, both the blue and red bands showed a decreasing trend because of an increasing package effect when pigment concentration in algal particles was elevated, but the decaying rate of optical absorption capacity was much faster on the blue band where optical absorption mainly associated with accessory pigments.

The variations of $a_{\mathrm{ph}}^{*}(\lambda)$ were also found to be significant due to different phytoplankton constituents at different seasons by $\mathrm{Wu}$ (2013), which are similar to those found in Taihu Lake [35] and Chagan Lake [36]. It was also shown that the package effect might explain the higher $a_{\mathrm{ph}}^{*}$ values at 440 or $676 \mathrm{~nm}$ in Poyang Lake at a certain level when Chl. a was relatively lower compared with that of the most other water bodies [23].
With those observations and analysis illustrated in this section, it would be reasonable to confirm that the absorption capacity of algal particulates in SPM was dependent on the relative contributions of accessory pigments and chlorophyll in phytoplankton composition as well as the package effect and could fluctuate on the feature bands of the spectrum under various aquatic environments during flood time.

There is, however, some ambiguity in the partition of the relative contribution of the package effect and accessory pigments, which could be possibly intermingled with each other in the domain of 400-500 nm, and further research including more effective separation among algal compositions such as sodium hypochlorite bleaching or numerical separation method warranted to resolve these problems [23, 32, 34].

\section{Conclusions}

This study presents a case study of optical variations of suspended particulate material absorption during the flood time for Poyang Lake and provides more insight into the natural changes of the spectral parameters required for the parameterization of bio-optical models and remote sensing algorithms in this dynamic water environment under the background of climate change and anthropogenic impacts.

As one of the most representative inland waters in China, Poyang Lake exhibits an overall high level of suspended nonalgal detritus and algal concentration and lower water clarity during study periods, showing a strong absorption by total suspended sediments that are closely related with the land-derived nonalgal detritus material which varied 


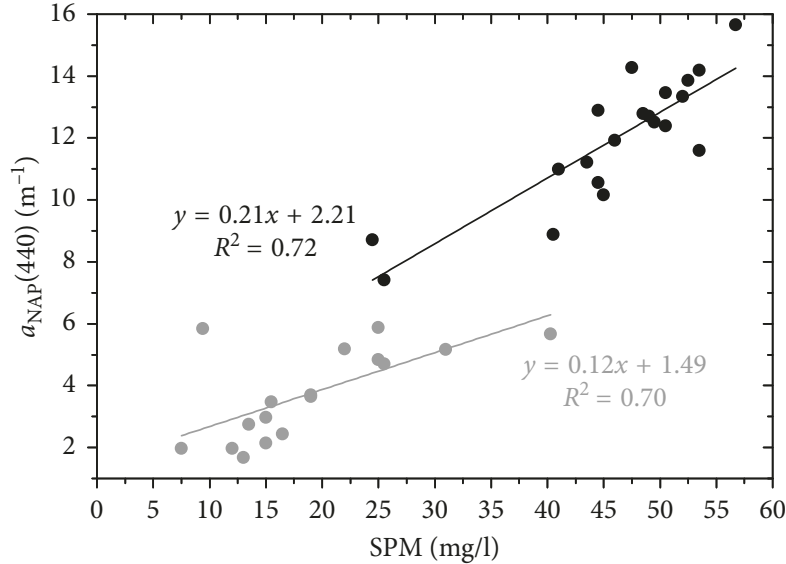

- July data

- Linear fit in July

- September data

_ Linear fit in September

(a)

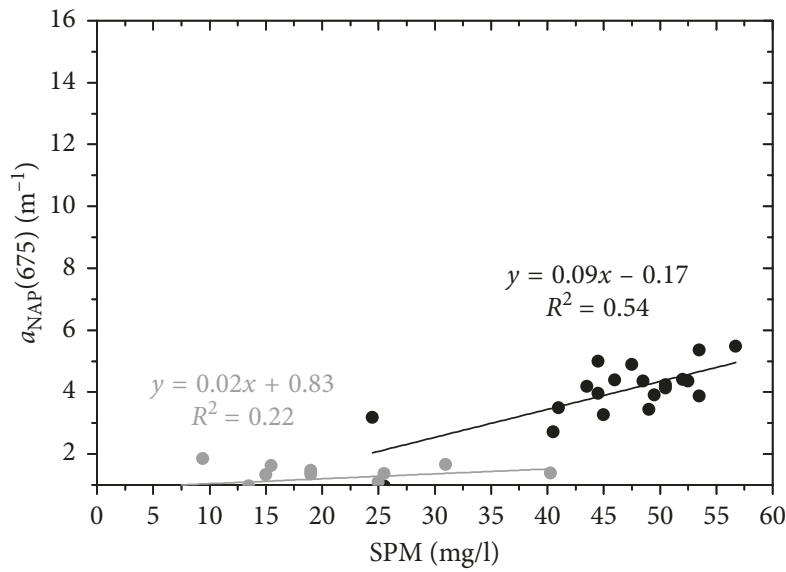

- July data Linear fit in July

(c)

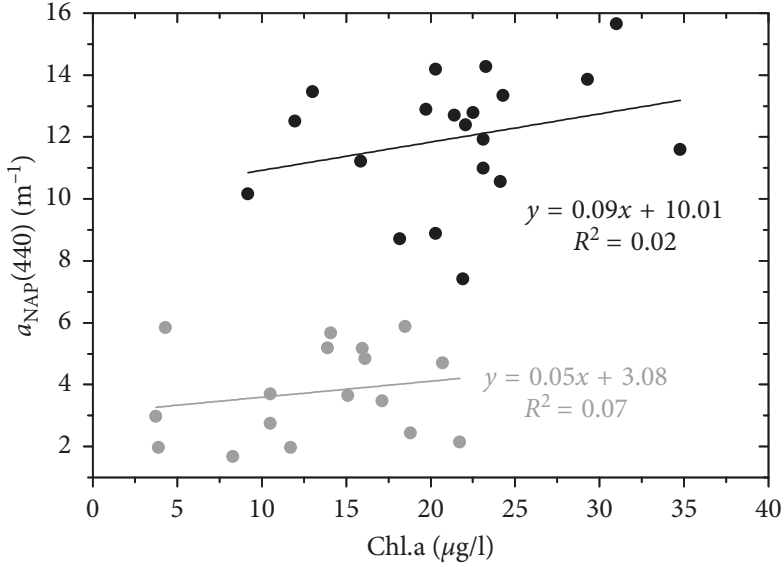

- July data

— Linear fit in July

- September data

_ Linear fit in September

(b)

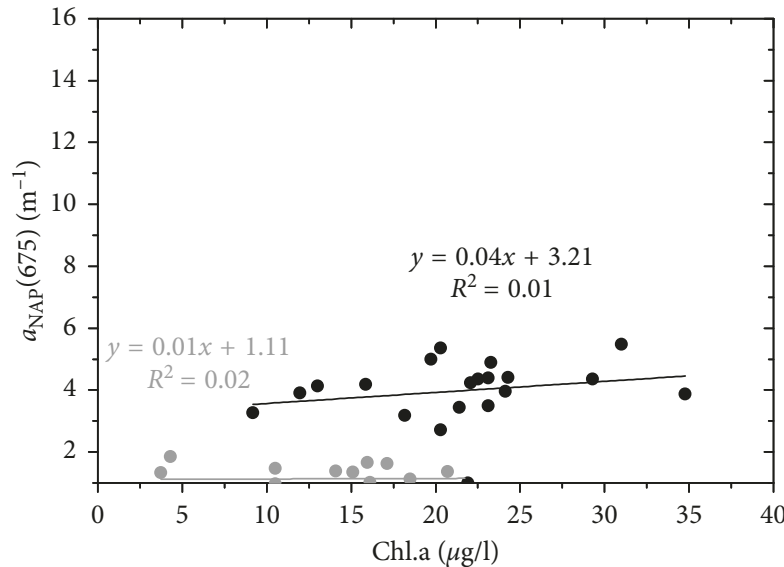

- July data

_ Linear fit in July

- September data

_ Linear fit in September

(d)

FIGURE 5: The linear relationships of $a_{\mathrm{NAP}}(440)$ and $a_{\mathrm{NAP}}(675)$ with SPM and Chl.a concentrations.

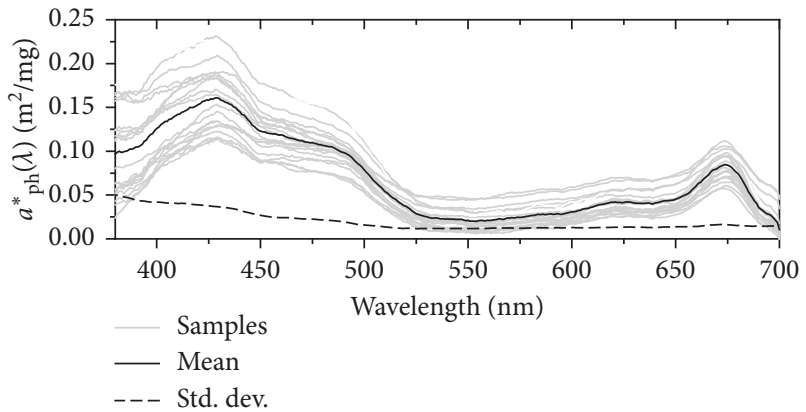

(a)

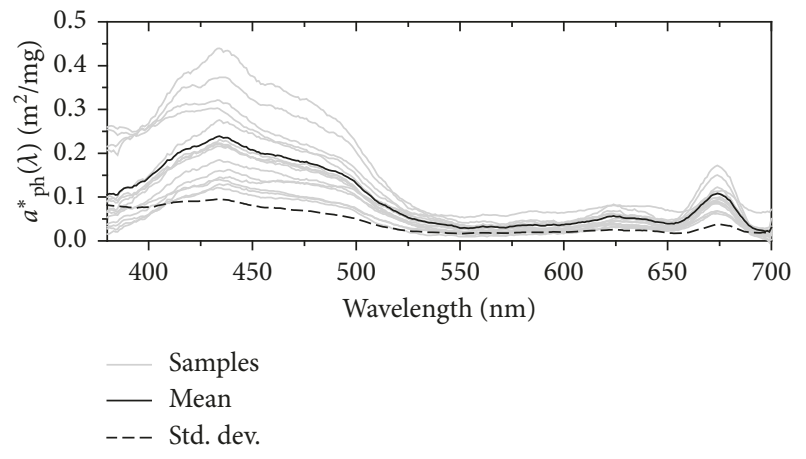

(b)

FIGURE 6: Phytoplankton specific absorption spectral curves in July (a) and September (b).

significantly with diverse proportions of minerals and organic materials from multiple sources loaded by river runoff injections, such as soil surface inorganic mineral salts
$[23,24]$, reactants, nonpoint source pollutions, or decompositions of biodegradable organic compounds $[4,30,32,34]$. 


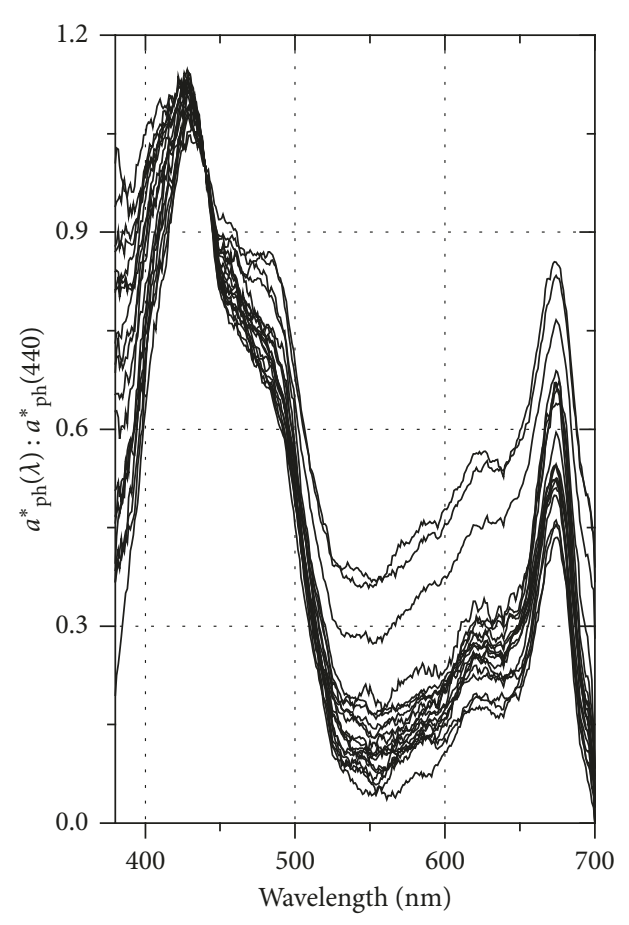

(a)

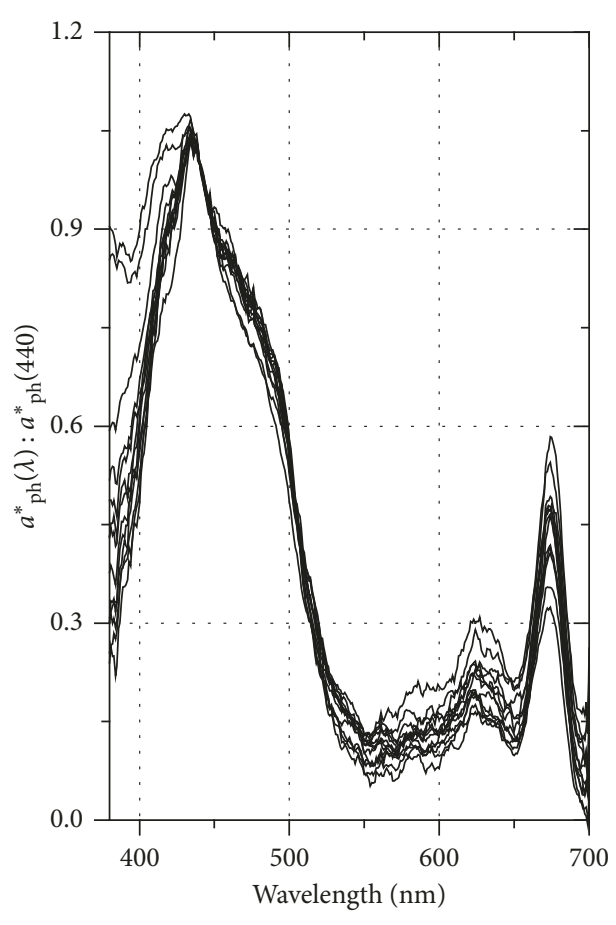

(b)

Figure 7: Specific absorption spectra normalized to $a_{\mathrm{ph}}^{*}(440)$ in July (a) and September (b).

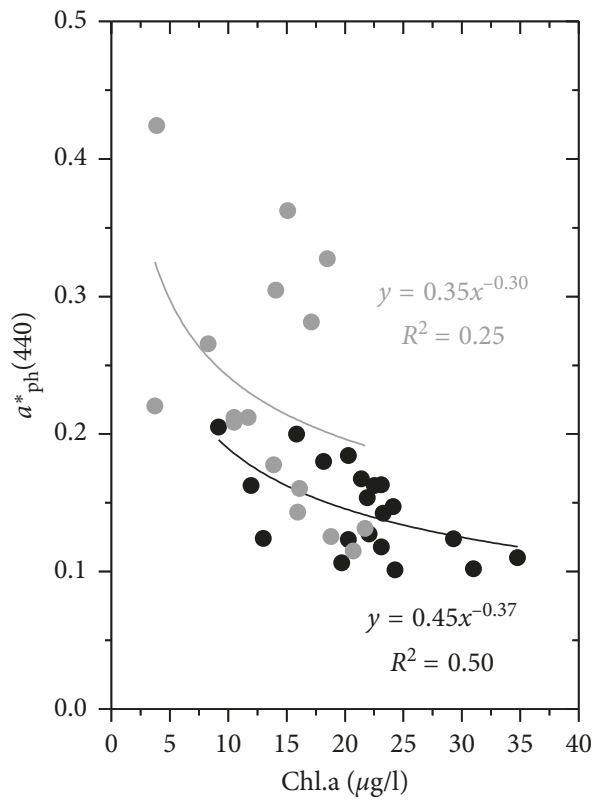

- July data

Power fit in July

- September data

_ Power fit in September

(a)

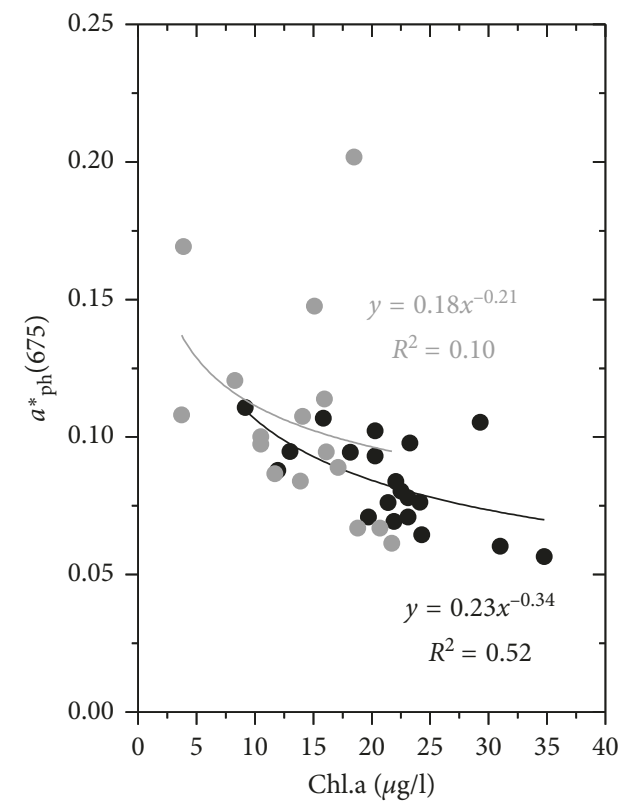

- July data

- Power fit in July

- September data

_ Power fit in September

(b)

Figure 8: The power functions of $a_{\mathrm{ph}}^{*}(440), a_{\mathrm{ph}}^{*}(675)$, and Chl.a. 
Due to variations in phytoplankton community pigment composition, concentration, and package effect, there exists a difference between optical absorption capacity on blue (440) and red (675) portions of bands, the former of which had an obvious enhancement due to the increased effect of accessory pigments (Chl.b, Chl.c, and carotenoids) in suspended phytoplankton particles from July to September.

Evidence also presented that the nonlinear dependency of specific phytoplankton particulate absorption on pigment concentration for various trophic statuses in different periods could be unstable due to relative contributions of the package effect and accessory pigments, and this could bring uncertainties to the application accuracy of bio-optical models and remote sensing algorithms during parameterization.

There is still some ambiguity in the partition of the relative contribution of the package effect and accessory pigments, which might be intermingled in the domain of 400-500 nm, and further research including more effective separation among algal composition such as sodium hypochlorite bleaching or numerical separation method warranted to resolve these problems $[23,32,34]$.

More works and studies are being carried out by researchers to learn about the spectral behavior of covaried optical active constituents present in this aquatic region, such as the identification of selective absorption of the dissolved organic material (DOM) onto sediments due to seasonal and dynamic biological activity (the presence of phytoplankton-derived DOM further processed by bacteria and/or by photo-oxidation) [27] and periodical covariation links between optical active materials [36], from which we hope to learn more about the impact of IOP variation on regional bio-optical model constructions and the interpretation of remote sensing observations in a changing environment.

\section{Data Availability}

All data generated or analyzed during this study are included in this article, and the original data are available from the corresponding author upon reasonable request.

\section{Conflicts of Interest}

The authors declare that they have no conflicts of interest.

\section{Authors' Contributions}

Yuandong Wang and Xibin You conceived and designed the experiments. Lianfang $\mathrm{Yu}$ performed the experiments. Yuandong Wang and Lihong Meng analyzed the data. Xiangming $\mathrm{Xu}$ contributed to the reagents and materials. Yuandong Wang and Guangxu Liu wrote and revised the paper.

\section{Acknowledgments}

This research was supported by the Science and Technology Planning Project of Jiangxi Provincial Education Department (No. GJJ151016) and the httpNational Natural
Science Foundation of China (Grant Nos. 41601600, 41561020, and 41301226).

\section{References}

[1] H. R. Gordon, O. B. Brown, and R. H. Evans, "A semianalytic radiance model of ocean color," Journal of Geophysical Research, vol. 93, no. D9, p. 10909, 1988.

[2] T. T John, B. M Colleen, and S. M. Timthy, "Remote sensing of physical cycles in lake superior using a spatio temporal analysis of optical water typologies," Remote Sensing of Environment, vol. 171, pp. 149-161, 2015.

[3] P Ammenberg, P Flink, and T. Lindell, "Bio-optical modelling combined with remote sensing to assess water quality," International Journal of Remote Sensing, vol. 23, no. 8, pp. 1621-1638, 2002.

[4] L. Hubert, M. Antoine, and V. Vincent, "Variability of suspended particulate material concentration in coastal waters under the Mekong's influence from ocean color (MERIS) remote sensing over the last decade," Remote Sensing of Environment, vol. 150, pp. 218-230, 2014.

[5] S. C. Palmer, P. D. Hunter, and T. Lankester, "Validation of Envisat MERIS algorithms for chlorophyll retrieval in a large, turbid and optically-complex shallow lake," Remote Sensing of Environment, vol. 157, pp. 158-169, 2015.

[6] A. Morel, "Optical modeling of the upper ocean in relation to its biogenous material content (Case I waters)," Journal of Geophysical Research, vol. 93, no. C9, pp. 10749-10768, 1988.

[7] B. G. Mitchell, A. Bricaud, K. Carder et al., "Determination of spectral absorption coefficients of particles, dissolved material and phytoplankton for discrete water samples," in Ocean Optics Protocols For Satellite Ocean Color Sensor Validation, Revision 2, NASA Technical Memorandum 2000-209966, G. S. Fargion, J. L. Mueller, and C. R. McClain, Eds., pp. 125-153, NASA Goddard Space Flight Center, Greenbelt, MD, USA, 2000.

[8] R. A. Reynolds, D. Stramski, and E. B. G. Mitchell, “A chlorophyll-dependent semianalytical reflectance model derived from field measurement of absorption and backscattering coefficients within the Southern Ocean," Journal of Geophysical Research, vol. 106, no. C4, pp. 7125-7138, 2001.

[9] A. Morel and S. Maritorena, "Bio-optical properties of oceanic waters: a reappraisal," Journal of Geophysical Research, vol. 106, no. C4, pp. 7163-7180, 2001.

[10] C. J. Stephanie, T. K. Palmer, and D. H. Peter, "Remote sensing of inland waters: challenges, progress and future directions," Remote Sensing of Environment, vol. 157, pp. 1-8, 2015.

[11] S. Bagheri, C. Zetlin, and R. Dios, "Estimation of optical properties of nearshore water," International Journal of Remote Sensing, vol. 20, no. 17, pp. 3393-3397, 2010.

[12] B. P. David, F. R. James, and A. G. Gower, "A review of ocean color remote sensing methods and statistical techniques for the detection, mapping and analysis of phytoplankton blooms in coastal and open oceans," Progress in Oceanography, vol. 123, no. 4, pp. 123-144, 2014.

[13] D. Katja and O. Natascha, "Remote sensing for lake research and monitoring-Recent advances," Ecological Indicators, vol. 64, pp. 105-122, 2016.

[14] D. G. Bowers, G. E. L. Harker, and B. Stephan, “Absorption spectra of inorganic particles in the Irish Sea and its relation to tidal stirring," International Journal of Remote Sensing, vol. 17, no. 12, pp. 2789-2805, 1996. 
[15] M. Babin, D. Stramski, G. M. Ferrari, and H. Claustre, "Variations in the light absorption coefficients of sssphytoplankton, non-algal particles, and dissolved organic material in coastal waters around Europe," Journal of Geophysical Research, vol. 108, no. C7, p. 3211, 2003.

[16] B. M. Colleen, G. Steven, and A. Dirk, "Aquatic color radiometry remote sensing of coastal and inland waters: Challenges and recommendations for future satellite missions," Remote Sensing of Environment, vol. 160, pp. 15-30, 2015.

[17] W. Zhang, X. L. Chen, L. Q. Tian et al., “Temporal and spatial variations of TSM concentration in Poyang Lake: observations from $\mathrm{HJ}-1 \mathrm{~A} / 1 \mathrm{~B}$ satellite CCD imagery," Journal of Central China Normal University (Natural Sciences), vol. 47, no. 3, pp. 416-420, 2013.

[18] W. X. Cao, Y. Z. Yang, and X. Q. Xu, "Regional patterns of phytoplankton spectral absorption in the Pearl river estuary," Chinese Science Bulletin, vol. 48, no. 17, pp. 1876-1882, 2003.

[19] G. P. Wu and Y. B. Liu, "Capturing variations in inundation with satellite remote sensing in amorphologically complex, large lake," Journal of Hydrology, vol. 523, no. 6, pp. 14-23, 2015.

[20] D. Stramski, S. B. Wozniak, and P. J. Flatau, "Optical properties of Asian mineral dust suspended in seawater," Limnology and Oceanography, vol. 49, no. 3, pp. 749-755, 2004.

[21] L. Linhai, L. Lin, S. Kaishan, and L. Yunmei, "An inversion model for deriving inherent optical properties of inland waters: Establishment, validation and application," Remote Sensing of Environment, vol. 135, pp. 150-166, 2015.

[22] L. Q. Chen, X. L. Chen, and L. Q. Tian, "Partitioning of the suspended particulate spectral scattering coefficient in Poyang lake," Spectroscopy and Spectral Analysis, vol. 32, no. 3, pp. 729-733, 2012.

[23] G. F. Wu, L. J. Cui, H. T. Duan, T. Fei, and Y. L. Liu, "Specifc absorption and backscattering coefficients of the main water constituents in Poyang lake, China," Environmental Monitoring and Assessment, vol. 185, no. C13, pp. 4191-4206, 2013.

[24] G. F. Wu, L. J. Cui, J. J. He, H. T. Duan et al., "Comparison of MODIS-based models for retrieving suspended particulate matter concentrations in Poyang lake, China," International Journal of Applied Earth Observation and Geoinformation, vol. 24, no. 1, pp. 63-72, 2013.

[25] G. Claudia, B. Mariano, and V. Emiliana, "Airborne hyperspectral data to assess suspended particulate material and aquatic vegetation in a shallow and turbid lake," Remote Sensing of Environment, vol. 157, pp. 48-57, 2015.

[26] Z. Wu, Y. Cai, X. Liu, C. P. Xu, Y. Chen, and L. Zhang, "Temporal and spatial variability of phytoplankton in Lake Poyang: the largest freshwater lake in China," Journal of Great Lakes Research, vol. 39, no. 3, pp. 476-483, 2013.

[27] J. Xu, Y. Q. Wang, D. Gao, Z. R. Yan, C. Gao, and L. L. Wang, "Optical properties and spatial distribution of chromophoric dissolved organic matter (CDOM) in Poyang lake, China," Journal of Great Lakes Research, vol. 43, no. 4, pp. 700-709, 2017.

[28] X. Mei, Z. Dai, J. Du, and J. Chen, "Linkage between Three Gorges Dam impacts and the dramatic recessions in China's largest freshwater lake, Poyang Lake," Scientific Reports, vol. 5, 2015.

[29] S. Lei, X. P. Zhang, and R. F. Li, "Analysis the changes of annual for Poyang lake wetland-vegetation based on MODIS monitoring," Procedia Environmental Sciences, vol. 10, no. 4, pp. 1840-1846, 2011.
[30] A. Beldjazia and D. Alatou, "Precipitation variability on the massif Forest of Mahouna (North Eastern-Algeria) from 1986 to 2010," International Journal of Management Sciences and Business Research, vol. 5, no. 3, pp. 21-28, 2016.

[31] C. S. Roesler, "Theoretical and experimental approaches to improve the accuracy of particulate absorption coefficients derived from the quantitative filter technique," Limnology \& Oceanography, vol. 43, pp. 1649-1660, 1998.

[32] B. G. Mitchel, M. Kahru, and J. Wieland, Determination of spectral absorption coefficients of particles, dissolved material and phytoplankton for discrete water samples. Ocean optics protocols for satellite ocean colour sensor validation, Revision 4, Volume IV: Inherent optical properties: Instruments, characterizations, field measurements and data analysis protocols, Goddard Space Flight Center Technical Memorandum, 01674, 2003.

[33] W. M. Mark, "Eutrophication and cyanobacterial blooms in South African inland waters: 10 years of MERIS observations," Remote Sensing of Environment, vol. 155, pp. 161-171, 2014.

[34] A. Bricaud, A. Morel, and M. Babin, "Variations of light absorption by suspended particles with chlorophyll a concentration in oceanic (case 1) waters: analysis and implications for bio-optical models," Journal of Geophysical Research, vol. 103, no. C13, pp. 31033-31044, 1998.

[35] R. H. Ma, D. L. Pan, H. T. Duan et al., "Absorption and scattering properties of water body in Taihu lake, China: backscattering," International Journal of Remote Sensing, vol. 30, no. 9, pp. 2321-2335, 2009.

[36] Y. D. Wang, D. W. Liu, K. S. Song, J. Du et al., "Characterization of water constituents spectra absorption in Chagan lake of Jilin province, Northeast China," Chinese Geographical Science, vol. 21, no. 3, pp. 334-345, 2011. 


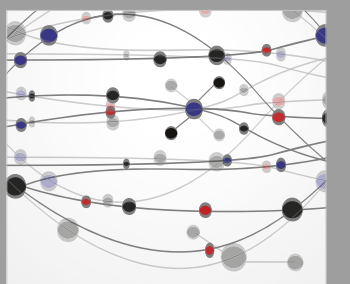

The Scientific World Journal
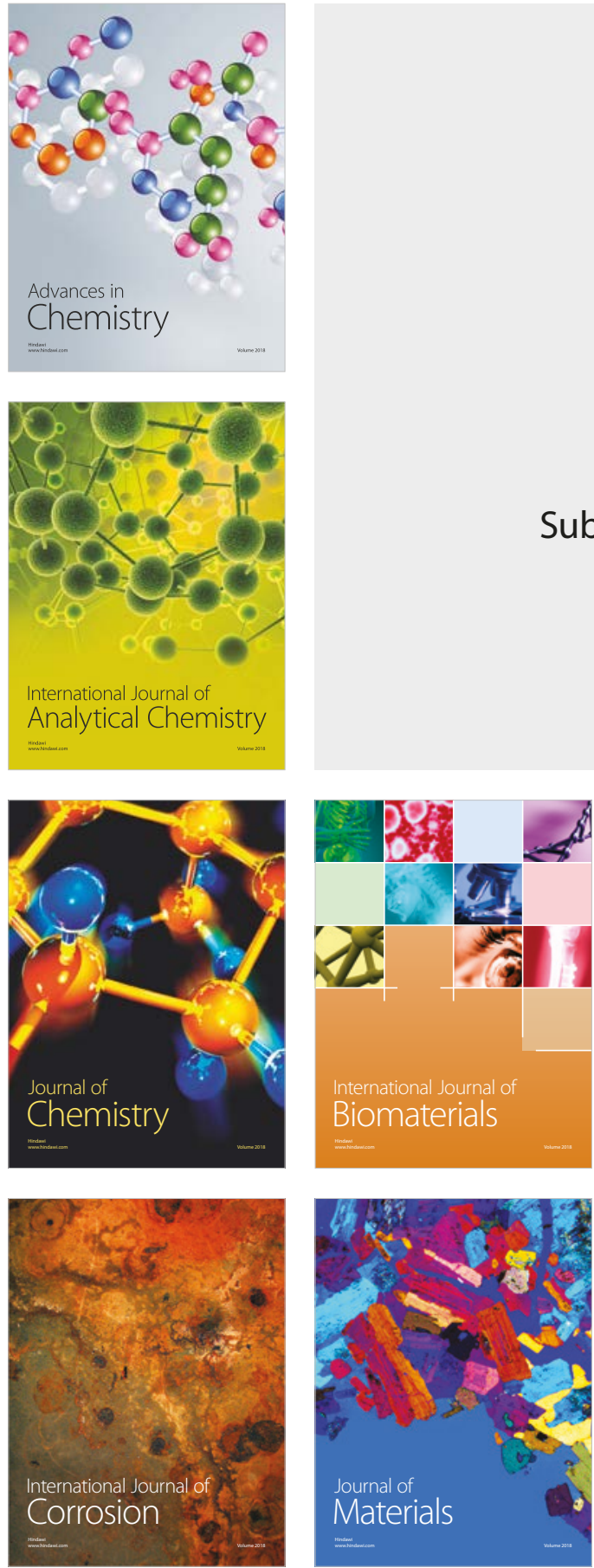

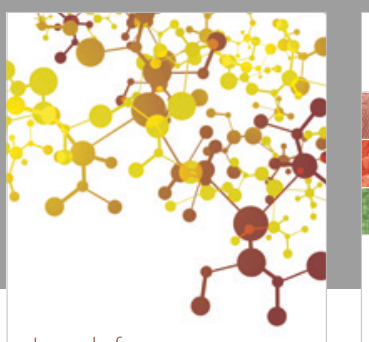

Journal of

Applied Chemistry
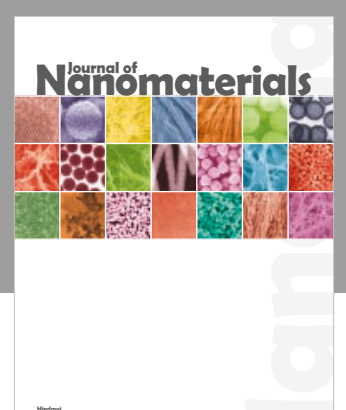

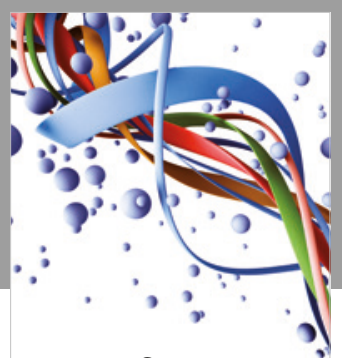

Scientifica

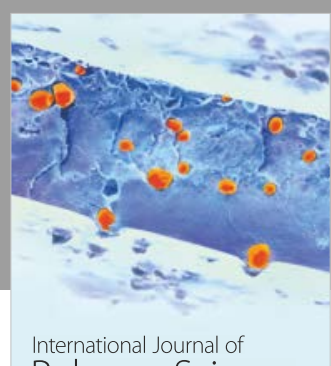

Polymer Science

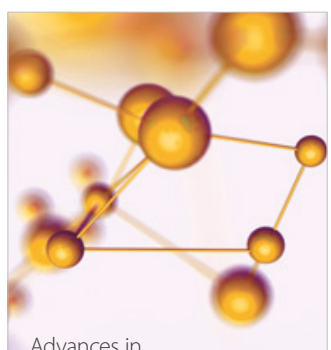

Physical Chemistry
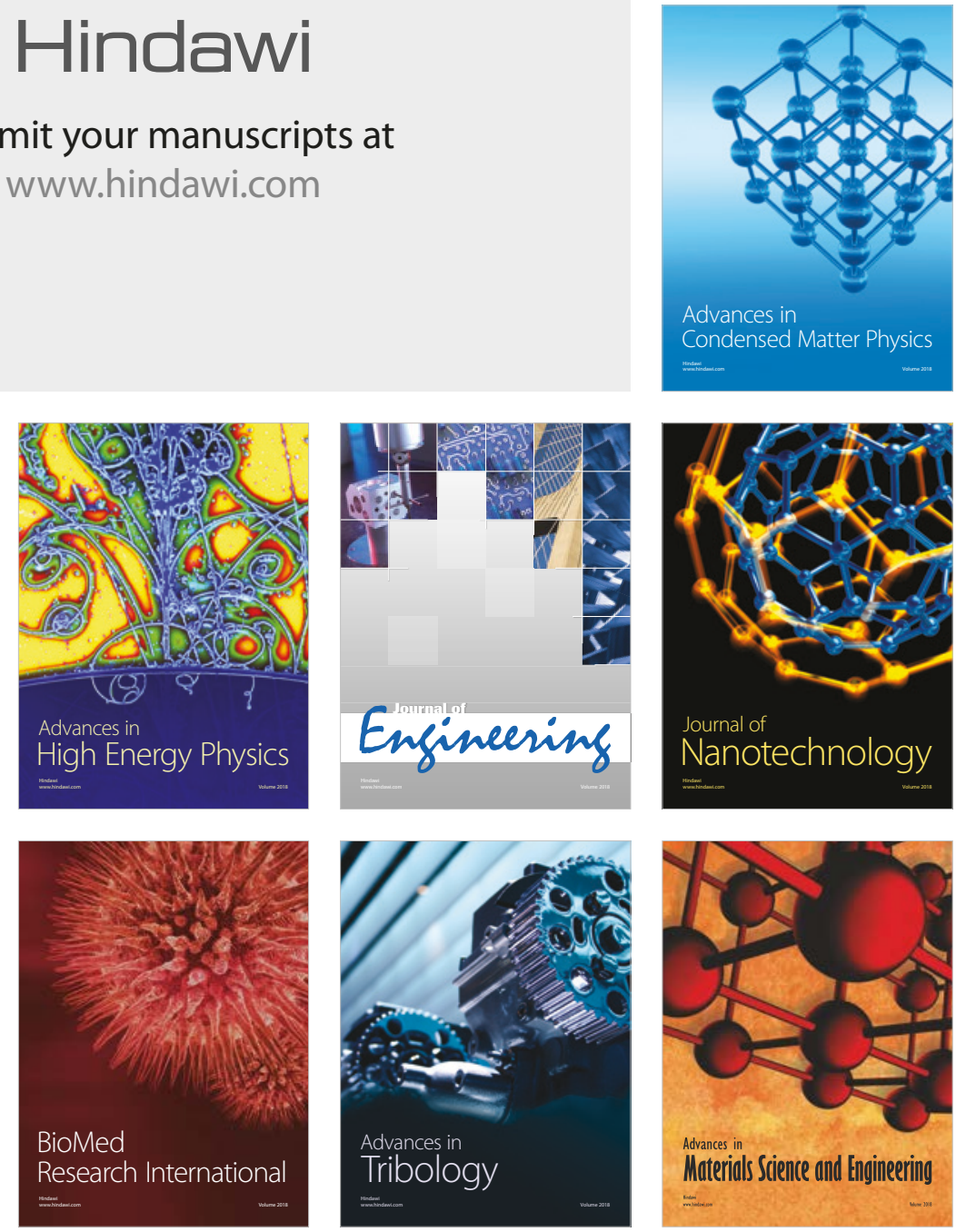